\title{
Analysis of functions of healthy office furniture based on analytic hierarchy process
}

\author{
Wang Chunpeng ${ }^{1}$, Xu Qing ${ }^{2}$ \\ ${ }^{1}$ Qingdao University of Technology, Qingdao City, Shandong Province, China, 266033 \\ ${ }^{2}$ Qingdao University of Technology, Qingdao City, Shandong Province, China, 266033
}

\begin{abstract}
In this digital information age, electronic devices can improve the work efficiency and reduce work load in business, but sedentary and long-time work style undermines the health of white-collar workers in the office. By combining qualitative and quantitative analysis, we aimed to identify the factors affecting health of white-collar workers in the office. Based on user demands, we summarized the design concepts for office furniture, pre-selected functions of the furniture, built a layered function model for healthy office furniture, and performed weight calculation on the criterion layer and the measure layers. The analytic hierarchy process method was used to sequence the functions of healthy office furniture to provide new design ideas and a basis for design of healthy office furniture.
\end{abstract}

\section{Introduction}

Work is an important part of people' lives. White-collar workers often sit in front of the screen and work more than half or more hours for eight hours a day. This is one of the reasons why more and more white-collar workers suffer from office syndromes. According to the prediction of the World Health Organization, more than $70 \%$ of physical diseases result from sedentary work by 2020 [1]. Office furniture, as an essential product for white-collar workers, can also play an important role in preventing occupational diseases. Therefore, our research integrates a healthy concept into the design of office furniture, so that office furniture has practical value and significance. Office furniture may play an important role in preventing occupational diseases. Therefore, this research integrates health concepts into office furniture and make it more practical value and significance.

In the late 1990s, "Healthy Industrial Design (HID)" was proposed by Mr Alan Tye, Royal Industrial Designer [2]. Health industry design is also regarded as "health engineering" because it prioritizes health and pays attention to whether the product can help people maintain a healthy state. We found that in the office, the factors that affect the health of the office population mainly include environmental factors, man-machine factors, and work factors by using the analysis of the survey results of the office population. We analysed the mental state, work habits, behaviour habits, and office syndrome improvement measures of the office population. The office furniture design concepts oriented to the workers' health are shown in Table 1. 
Table 1. Healthy office furniture design concepts

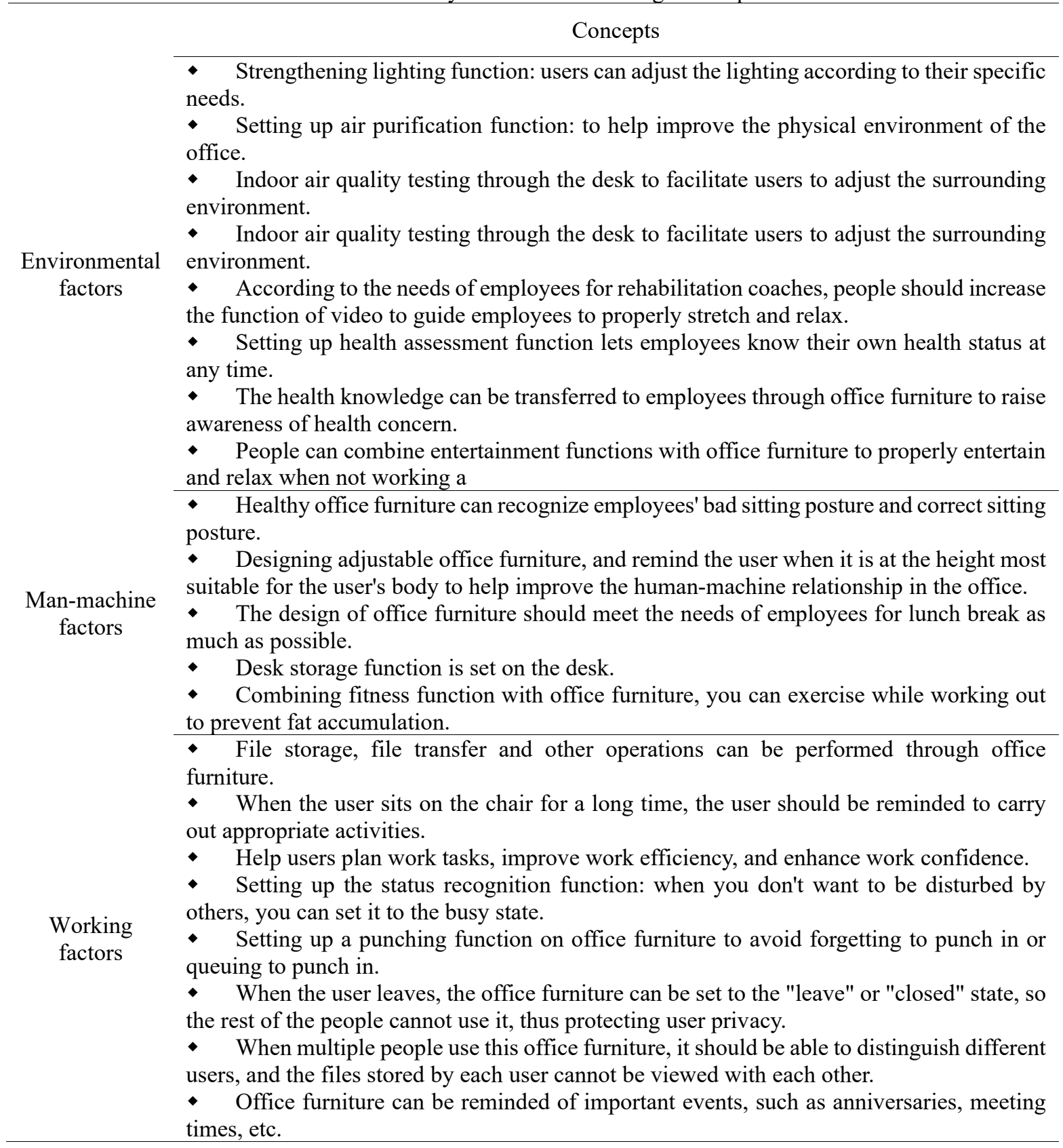

These concept points are converted into functions of office furniture products that are an important part of healthy office design. Through the quality function deployment (QFD), we identify research steps and seven functions based on the importance of the functions. The details are as follows.

Quality function development, called the QFD method, is a method that uses a matrix to quantify various indicators affecting the product and to meet the customer's maximum demands during the product development process. Further, specific solutions should be proposed. QFD can not only help companies locate customer needs and choose solutions, but also break communication barriers between departments. This can reduce design period, uncertainty, and investment costs, improving product quality and user satisfaction.

There are several typical quality management tools under the QFD framework. As shown in Table 2, each tool has a different role. According to the needs of this article, the chromatographic analysis method will be adopted as a tool for functional sequencing.

Table 2. Typical quality management tools under the QFD framework

\begin{tabular}{cl}
\hline Title & \multicolumn{1}{c}{ Features } \\
\hline Affinity diagram KJ & $\begin{array}{l}\text { Identifying the essence of complex problems and collect different } \\
\text { opinions, ideas and experiences, more suitable for unknown fields }\end{array}$ \\
\hline
\end{tabular}




\begin{tabular}{cl}
\hline Relation diagram & $\begin{array}{l}\text { Finding the problem that affects the quality from the horizontal causal } \\
\text { relationship between the problems, suitable for analyzing complex } \\
\text { problems intertwined by multiple factors }\end{array}$ \\
\hline $\begin{array}{c}\text { System diagram (tree } \\
\text { diagram) }\end{array}$ & $\begin{array}{l}\text { Systematical identifying the problem, looking for specific means that can } \\
\text { solve the problem, and form a "purpose-means" diagram }\end{array}$ \\
\hline Matrix diagram & $\begin{array}{l}\text { Looking for paired factors to construct a matrix diagram, comprehensively } \\
\text { analyze multi-factor associations, and find key points }\end{array}$ \\
\hline $\begin{array}{c}\text { Process decision } \\
\text { procedure diagram }\end{array}$ & $\begin{array}{l}\text { Anticipating obstacles and possible outcomes during development and } \\
\text { design, avoid major mistakes }\end{array}$ \\
\hline $\begin{array}{c}\text { Analytic hierarchy } \\
\text { process }\end{array}$ & $\begin{array}{l}\text { It can handle complex decision-making problems, suitable for prioritizing } \\
\text { subjective information }\end{array}$ \\
\hline Blueprint & $\begin{array}{l}\text { Describing the service process in detail, and transforming the invisible } \\
\text { service into specific steps and methods }\end{array}$ \\
\hline The House of Quality & $\begin{array}{l}\text { In the process of product design and development, it is used to connect } \\
\text { user needs and corresponding product functions or services }\end{array}$ \\
\hline
\end{tabular}

\section{Analytic hierarchy process}

Analytical Hierarchy Process (AHP) was proposed by American operations researcher T.L. Saaty in the mid1970s. AHP is competent to deal with complex decisionmaking problems. It can implement system analysis by assigning values to certain qualitative factors [3]. It is suitable for subjective problems and situations with uncertain factors, and it has a logical layering of complex problems. The method also has the advantages of organization, which can make the selection process more visual and concise. This method is not only can resolve subjective problems and situations with uncertain factors, but also can make complex problems logical, hierarchical and organized, making the selection process more concise and clearer.

As a mixed method of qualitative analysis and quantitative analysis, AHP can not only avoid the limitations of qualitative analysis but also have the scientific reliability of quantitative analysis [4]. The analytic hierarchy process analyzes the weights of the selected functions and optimizes the order of core functions, main functions, secondary functions and auxiliary functions of the product. The purpose is to understand the needs of customers and distinguish primary and secondary. Then, designers can allocate their work. Finally, we hope to achieve the maximum users' satisfaction at the least cost.

\section{Apply AHP can determine the functional weighted ranking of healthy office furniture}

\subsection{Product function preselection}

Although the above summarizes the design concepts of 20 healthy office furniture, when we try to design furniture, it is unlikely to use all the conceptual functions on one product.

Therefore, if we would like to design a kind of office furniture that can be deeply liked by office workers and really resolve their difficulties, we first upgrade the concepts into conceptual functions and then we need to screen the conceptual functions. During this process, there may be several concepts combining into a conceptual function. The process of function selection is in the form of a questionnaire. It requires opinions from white-collar workers with a sedentary job. Employees are asked to choose the three functions they most expect from all the conceptual functions. The conceptual function and questionnaire form is shown in Figure 1: 


\section{Voting for Functions of Healthy Office Furniture}

$\mathrm{Hi}$, this is a vote for the functional screening of healthy office furniture. Healthy office furniture aims to promote healthy working methods and improve work efficiency in the office. To identify the most suitable functions, we invite you to take part in this vote. Thank you for your support.

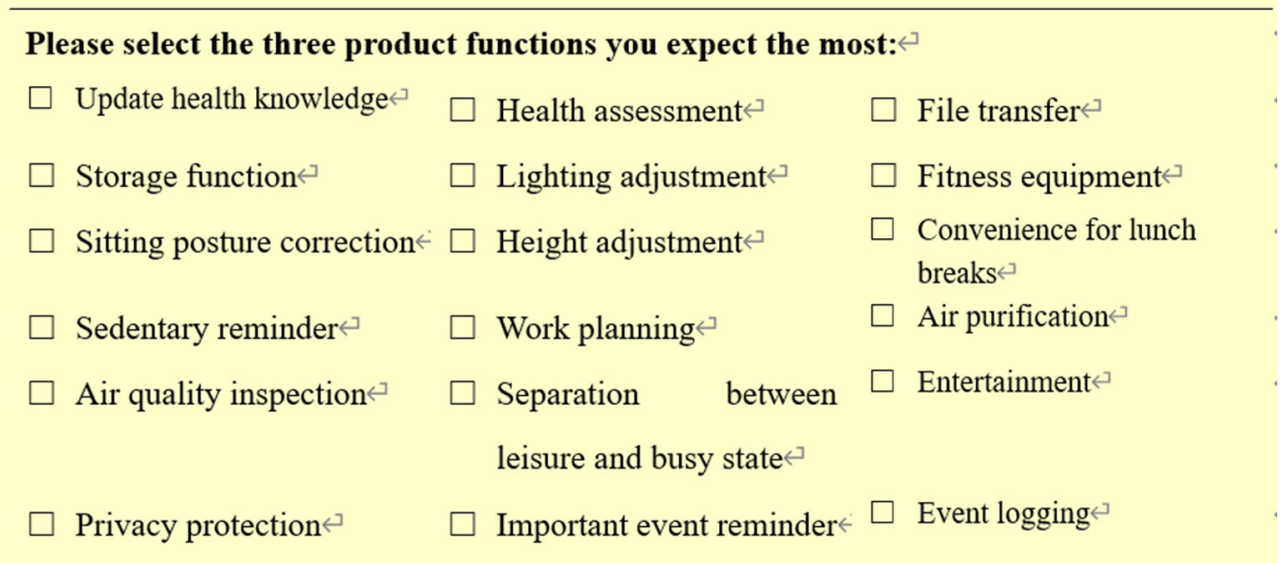

Figure 1. Questionnaire for functions of healthy office furniture

In this survey, there are 120 participants in the voting. As survey results in Figure 2 show, the seven functions with the most votes are sedentary reminder, height

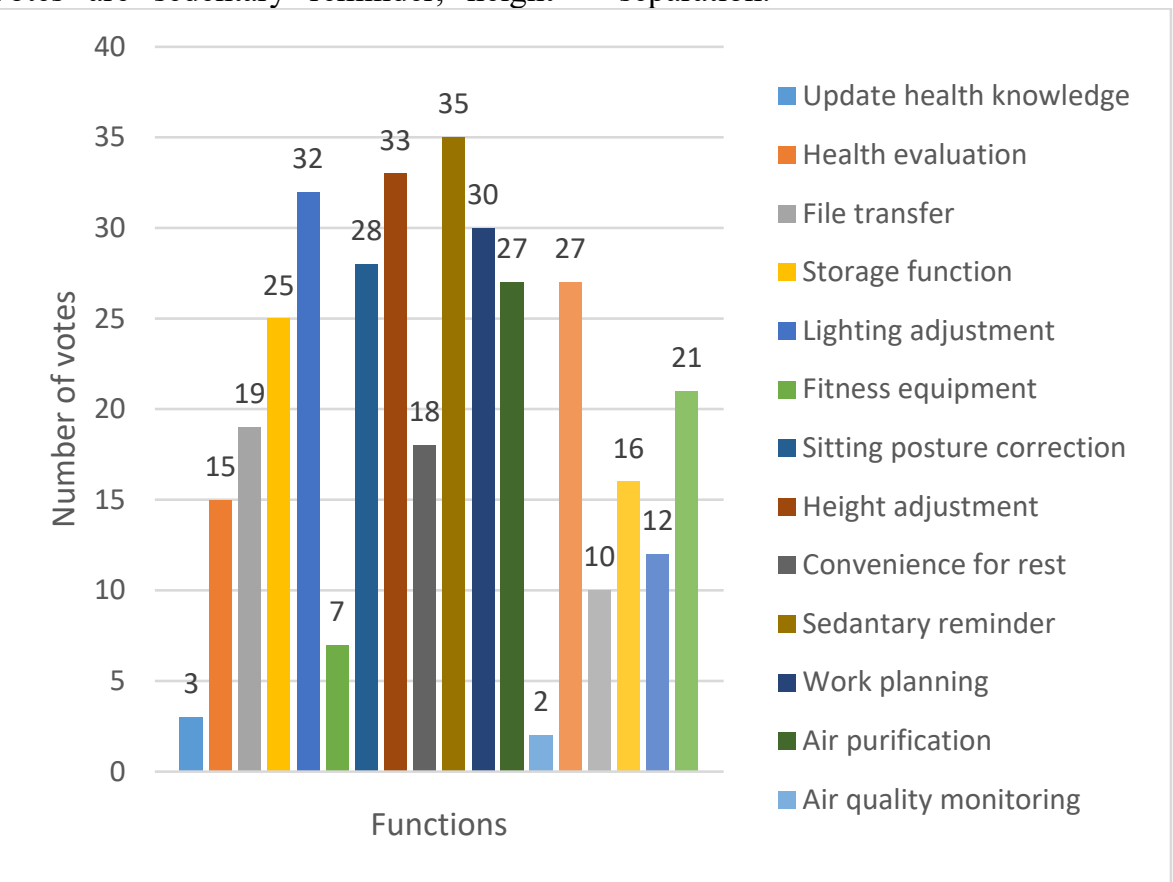

Figure 2. Survey result for functions of healthy office furniture
3.2 Building a hierarchy model of healthy office furniture The goal of the design of healthy office furniture is to design a way to guide office workers to have healthy work, which can help users efficiently complete heavy work tasks. Therefore, the target layer of the constructed hierarchical structure model is "healthy and efficient work". Through the analysis of the survey results, it is concluded that there are three factors that affect the health of office workers, including environmental factors, human-machine factors, and work factors. Therefore, we take these three factors as the criterion level indicators of adjustment, lighting adjustment, work planning, sitting posture correction, air purification function and state separation. the hierarchical structure model. From the results of product function screening, seven product functions most anticipated by the target user can be drawn, including lighting adjustment, air purification, desktop adjustment, sitting posture correction, status differentiation, sedentary reminder, and planning work tasks. We classify these 7 functions according to their respective properties and use them as the measure level indicators of the hierarchical structure model. The hierarchical structure model can be built from top to bottom by the AHP method, as shown in Figure 3. 


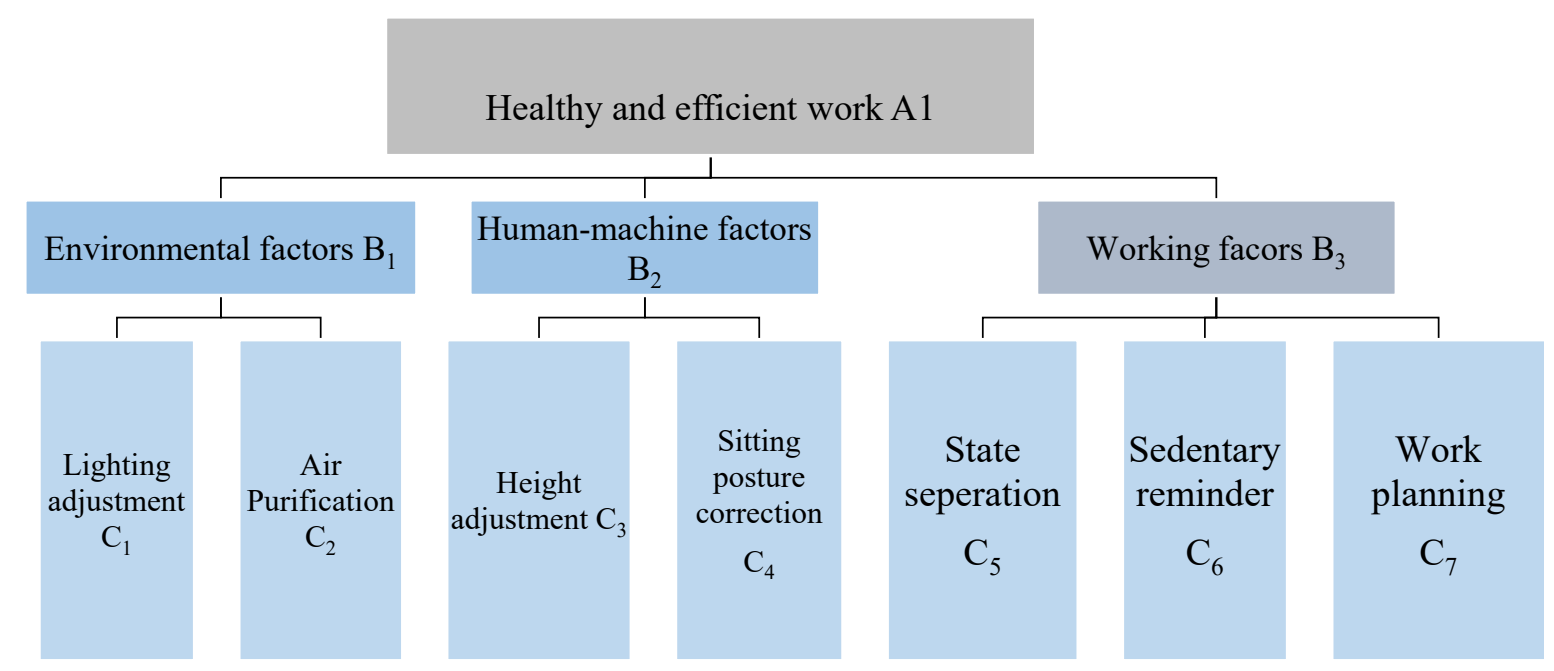

Figure 3 Layered structure model for functions of healthy furniture

3.3 Criteria-layer weight calculation

3.3.1 Constructing a judgment matrix
After establishing the hierarchical structure model, the importance of each level index in the model can be investigated, and then the judgment matrix can be constructed. The method of pairing comparison is used to judge the importance degree. For the assignment criteria, we can refer to Saaty's 1-9 comparison scale (Table 3) [5].

Table 3. Comparison Scale

\begin{tabular}{|c|c|}
\hline $\begin{array}{l}\text { Importance } \\
\text { scale }\end{array}$ & Meaning \\
\hline 1 & Two elements are equally important \\
\hline 3 & The former element is slightly more important than the latter \\
\hline 5 & The former ELEMENT is obviously more important than the latter \\
\hline 7 & The former element is more important than the latter \\
\hline 9 & The former element is more important than the latter \\
\hline $2,4,6,8$ & Median \\
\hline Reciprocal & $\begin{array}{l}\text { If the ratio of the importance of element } i \text { to element } j \text { is } a \text {, then the ratio of the importance } \\
\text { of element } j \text { to element } i \text { is } 1 / a\end{array}$ \\
\hline
\end{tabular}

Because this layer of indicators is not accurate to specific functions, the expert evaluation method is used. We selected 10 target users who had design experience and needed to endure long-term sedentariness as survey subjects to conduct a survey. According to the principle of pairwise comparison, the comparison of the same element has the same importance, such as $\mathrm{C} 1 / \mathrm{C} 1=1$. The important product of two elements that are opposite to each other is 1 , such as $\mathrm{B} 1 / \mathrm{B} 2 \times \mathrm{B} 2 / \mathrm{B} 1=1$, which can be simplified when designing the questionnaire. The specific questionnaire form is shown in Table 4.

Table 4. Questionnaire for comparison of criteria layer elements.

\begin{tabular}{llllll}
\hline $\begin{array}{l}\text { Paired elements } / \\
\text { scale }\end{array}$ & $\begin{array}{l}1 \\
\text { Equally } \\
\text { important }\end{array}$ & $\begin{array}{l}3 \\
\text { Slightly } \\
\text { important }\end{array}$ & $\begin{array}{l}\text { Obviously } \\
\text { important }\end{array}$ & $\begin{array}{l}\text { Strongly } \\
\text { important }\end{array}$ & $\begin{array}{l}\text { Extremely } \\
\text { important }\end{array}$ \\
\hline $\mathrm{B}_{2} / \mathrm{B}_{1}$ & & & & \\
$\mathrm{~B}_{3} / \mathrm{B}_{1}$ & & & \\
$\mathrm{~B}_{2} / \mathrm{B}_{3}$ & & & \\
\hline
\end{tabular}

Note: $\mathrm{B}_{1}$ is environmental factors; $\mathrm{B}_{2}$ is man-machine factors; $\mathrm{B}_{3}$ is working factors 
The expert scoring records are detailed in Table 5. The average value of the collected data is calculated, and the decimal point is rounded to obtain the weight of each comparison element in the criterion layer, as shown in Table 6:

Table 5. Criteria-layer expert scoring statistics

\begin{tabular}{llllllllllll}
\hline Comparison group & 1 & 2 & 3 & 4 & 5 & 6 & 7 & 8 & 9 & 10 & Average value \\
\hline B2Man-machine /B1 environmental & 3 & 3 & 1 & 5 & 3 & 3 & 5 & 3 & 1 & 5 & 3.2 \\
B3 working /B1 environmental & 1 & 1 & 1 & 3 & 3 & 1 & 3 & 1 & 1 & 3 & 1.8 \\
\hline
\end{tabular}

Table 6. Criteria layer element contrast weight matrix.

\begin{tabular}{cccc}
\hline $\mathrm{A}$ & B1environment & B2Man-machine & B3working \\
\hline $\begin{array}{c}\text { B1 } \\
\text { environment }\end{array}$ & 1 & $1 / 3$ & $1 / 2$ \\
$\begin{array}{c}\text { B2 Man- } \\
\text { machine }\end{array}$ & 3 & 1 & 2 \\
B3 working & 2 & $1 / 2$ & 1 \\
\hline
\end{tabular}

\subsubsection{Data calculation}

The Equation (1) is split into calculations in order to make the calculation process clearer. The specific process is as follows:

$$
\omega_{i}=\frac{1}{n} \sum_{j=1}^{n} \frac{a_{i j}}{\sum_{k=1}^{n} a_{k j}}
$$

Step 1: Calculate the sum of each column of data

Table 7 Sum of the elements of each column

\begin{tabular}{llll}
\hline $\mathrm{A}$ & $\mathrm{B}_{1}$ & $\mathrm{~B}_{2}$ & $\mathrm{~B}_{3}$ \\
\hline $\mathrm{B}_{1}$ & 1 & $1 / 3$ & $1 / 2$ \\
$\mathrm{~B}_{2}$ & 3 & 1 & 2 \\
$\mathrm{~B}_{3}$ & 2 & $1 / 2$ & 1 \\
$\sum_{\mathrm{k}=1}^{\mathrm{n}} \mathrm{a}_{\mathrm{kj}}$ & 6 & $11 / 6$ & $7 / 2$
\end{tabular}

Step 2: Normalize each element in the data by column.

$$
\overline{a_{i j}}=a_{i j}\left(\sum_{k=1}^{n} a_{k j}\right)^{-1}(i, j=1,2, \ldots . ., n)
$$

Table 8. Normalization of each element by column

\begin{tabular}{llll}
\hline $\mathrm{A}$ & $\mathrm{B}_{1}$ & $\mathrm{~B}_{2}$ & $\mathrm{~B}_{3}$ \\
\hline $\mathrm{B}_{1}$ & $1 / 6$ & $2 / 11$ & $1 / 7$ \\
$\mathrm{~B}_{2}$ & $3 / 6$ & $6 / 11$ & $4 / 7$ \\
$\mathrm{~B}_{3}$ & $2 / 6$ & $3 / 11$ & $2 / 7$ \\
\hline
\end{tabular}

Step 3: Add the normalized values of the above elements in the same row by column

$$
\omega^{\prime \prime}=\sum_{j=1}^{n} \overline{a_{i j}}
$$




\begin{tabular}{lllll}
\multicolumn{5}{c}{ Table 9. Addition of normalized values of each row } \\
\hline $\mathrm{A}$ & $\mathrm{B}_{1}$ & $\mathrm{~B}_{2}$ & $\mathrm{~B}_{3}$ & $\omega_{\mathrm{i}}^{\prime}$ \\
& & & & \\
\hline $\mathrm{B}_{1}$ & 0.1667 & 0.1818 & 0.1429 & 0.4914 \\
$\mathrm{~B}_{2}$ & 0.5 & 0.5455 & 0.5714 & 1.6169 \\
$\mathrm{~B}_{3}$ & 0.3333 & 0.2727 & 0.2857 & 0.8917 \\
$\sum \overline{\mathrm{a}_{\mathrm{ij}}}$ & 1 & 1 & 1 & 3 \\
\hline
\end{tabular}

Step 4: Divide the result of the addition of each row by $n$ to get the weight of each element

Table 10. Weight values for each element

\begin{tabular}{lllll}
$\mathrm{A}$ & $\mathrm{B}_{1}$ & $\mathrm{~B}_{2}$ & $\omega_{\mathrm{i}}$ & $\omega_{\mathrm{i}}$ \\
\hline $\mathrm{B}_{1}$ & 0.1667 & 0.1818 & 0.4914 & 0.1638 \\
$\mathrm{~B}_{2}$ & 0.5 & 0.5455 & 1.6169 & 0.5390 \\
$\mathrm{~B}_{3}$ & 0.3333 & 0.2727 & 0.8917 & 0.2972 \\
\hline
\end{tabular}

\subsubsection{Judgment matrix consistency}

$$
\lambda_{\max }=\sum_{\mathrm{j}=1}^{\mathrm{n}} \frac{(A \omega)_{\mathrm{i}}}{\mathrm{n} \omega_{\mathrm{i}}}
$$$$
A \omega=\left[\begin{array}{ccc}
1 & 1 / 3 & 1 / 2 \\
3 & 1 & 2 \\
2 & 1 / 2 & 1
\end{array}\right] \cdot\left[\begin{array}{l}
0.1638 \\
0.5390 \\
0.2972
\end{array}\right]
$$

Step 1: According to formula (4), if you want to find the maximum eigenvalue max, you need first to calculate $(\mathrm{A} \omega)$, that is:
According to the principle of matrix multiplication calculation, we can get:

$(\mathrm{A} \omega)_{1}=1 \times 0.1638+1 / 3 \times 0.5390+1 / 2 \times 0.2972=0.4921$

$(\mathrm{A} \omega)_{2}=3 \times 0.1638+1 \times 0.5390+2 \times 0.2972=1.6248$

$(\mathrm{A} \omega)_{3}=2 \times 0.1638+1 / 2 \times 0.5390+1 \times 0.2972=0.8943$

Step 2: Calculate the maximum characteristic root max by formula (4), which:

$$
\lambda_{\max }=0.4921 /(3 \times 0.1638)+1.6248 /(3 \times 0.5390)
$$

$+0.8943 /(3 \times 0.2972)=3.0092$
Step 3: Calculate the consistency index CI according to formula (5), which:

$$
C I=\frac{\lambda_{\max }-\mathrm{n}}{\mathrm{n}-1}
$$

$\mathrm{CI}=(3.0092-3) /(3-1)=0.0046$

Step 4: Calculate the consistency ratio CR according to formula (4). Among them, RI can be seen by looking up Table 11 [6]. When the order is $3, \mathrm{RI}=0.52$. then: $\mathrm{CR}=0.0046 / 0.52=0.0088$

Table 11. RI table of average random consistency indicators.

\begin{tabular}{lllllllll}
\hline Matrix order & 1 & 2 & 3 & 4 & 5 & 6 & 7 & 8 \\
\hline RI & 0 & 0 & 0.52 & 0.89 & 1.12 & 1.26 & 1.36 & 1.41 \\
\hline
\end{tabular}

Step 5: According to the CR judgment principle, when $\mathrm{CR}$ is less than 0.1 , the consistency of the matrix can be accepted. Since 0.0088 is less than 0.1 , the above matrix is consistent, and the weight of each element is valid.

By sorting the elements of the criterion layer at a single level, experts believe that human-machine factors are the most important among the three influencing factors for employee health, accounting for $54 \%$; followed by work factors, accounting for $29.7 \%$. Finally, environmental factors account for $16.3 \%$. 


\section{Measure-layer weight calculation}

The criterion layer contains three elements. Because it is not easy for people to understand, we choose the expert evaluation method to assign elements to it. The elements in the measure layer are detailed seven specific functions, which are easy for the target group to understand. Therefore, we choose the general audience to assign the importance of the elements.

As shown in Figure 4, we did not choose the method of directly assigning values to pairs of elements for the importance of the elements. When two elements are compared, it is not easy for many people to distinguish the order of comparison between the elements, which not only increases the difficulty of the work but also is not conducive to ensuring the accuracy of the data. Therefore, this evaluation uses the method of the overall evaluation of all the elements of the measure layer. This form is dramatically concise, and it is easy for people to grasp the whole (see Appendix 1 for the complete evaluation table).

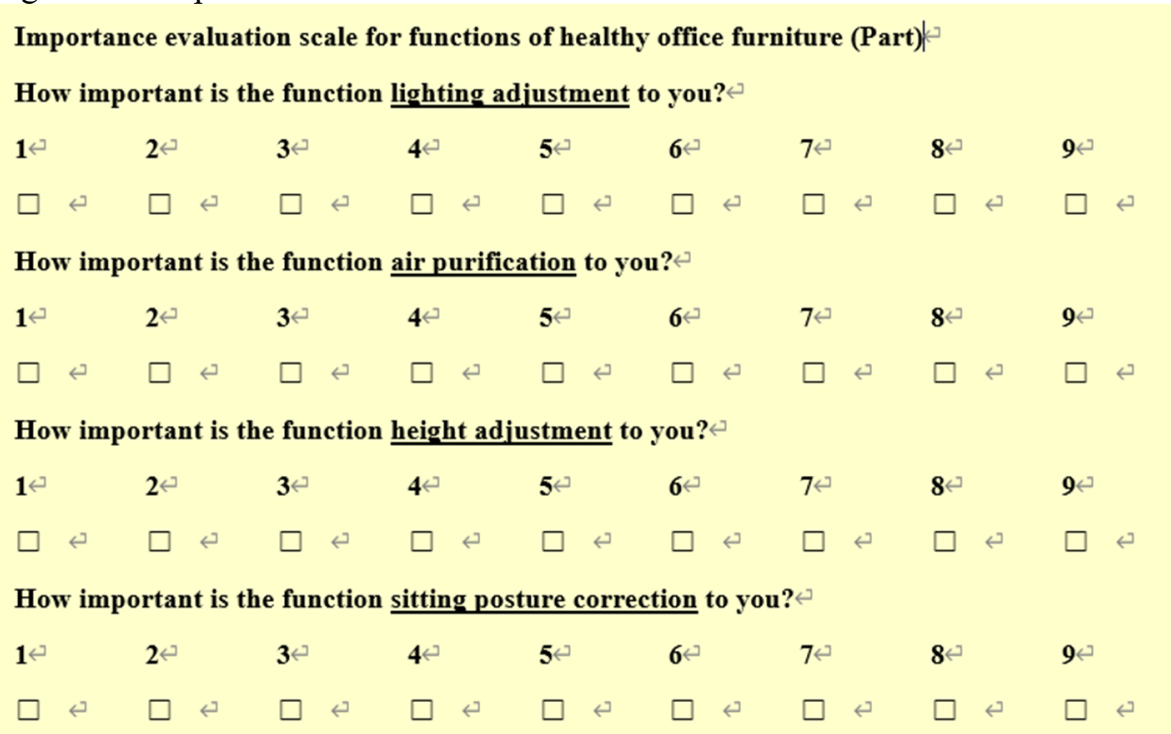

Figure 4. Importance evaluation scale for functions of healthy office furniture (Part)

A total of 30 typical target users were selected for the survey. We arrange the number of people for each important scale of functions, as shown in Table 12.

Table 12. Number of people voting for the importance of each element

\begin{tabular}{lccccccccc}
\hline Indicators & 1 & 2 & 3 & 4 & 5 & 6 & 7 & 8 & 9 \\
\hline Lighting adjustment $\mathrm{C}_{1}$ & 0 & 3 & 2 & 3 & 6 & 3 & 4 & 5 & 4 \\
Air purificationC $\mathrm{C}_{2}$ & 6 & 5 & 8 & 3 & 3 & 2 & 1 & 2 & 0 \\
Height adjustment $\mathrm{C}_{3}$ & 0 & 2 & 3 & 3 & 4 & 3 & 4 & 5 & 6 \\
Sitting posture correction $\mathrm{C}_{4}$ & 5 & 4 & 5 & 3 & 6 & 3 & 2 & 1 & 1 \\
Distinguish between leisure and & 4 & 5 & 5 & 4 & 3 & 3 & 2 & 3 & 1 \\
busy state $\mathrm{C}_{5}$ & 0 & 0 & 0 & 0 & 2 & 4 & 5 & 12 & 7 \\
Sedentary reminder $\mathrm{C}_{6}$ & 0 & 0 & 1 & 2 & 1 & 3 & 8 & 8 & 7 \\
Planning work $\mathrm{C}_{7}$ & & & & & & & & & \\
\hline
\end{tabular}

\subsection{Constructing the judgment matrix}

Sum up the above data and calculate the average, as shown in Table 13:

Table 13. Sum and average value of each group

\begin{tabular}{llllllll}
\hline & $\mathrm{C}_{1}$ & $\mathrm{C}_{2}$ & $\mathrm{C}_{3}$ & $\mathrm{C}_{4}$ & $\mathrm{C}_{5}$ & $\mathrm{C}_{6}$ & $\mathrm{C}_{7}$ \\
\hline $\mathrm{X}_{C_{1}}$ & 176 & 102 & 185 & 119 & 125 & 228 & 217 \\
$\overline{\mathrm{X}}_{{ }_{1}}$ & 5.8667 & 3.4 & \multirow{2}{*}{6.1667} & 3.9667 & 4.1667 & 7.6 & 7.2333 \\
\hline
\end{tabular}


According to the comparison scale table proposed by Saaty, when the importance of two elements is the same, the importance scale is 1 . Therefore, the value of two elements with different importance ranges from 2 to 9 . From the above table, the ratio of the two elements with the strongest contrast is $\mathrm{C} 6 / \mathrm{C} 2=228 / 30 \div 102 / 30=$ 228/102; the ratio of the two elements with the weakest contrast is C $5 / \mathrm{C} 4=125 / 30 \div 119 / 30=125 / 119$. Finally, we take the $\mathrm{X}$ axis as the comparison scale and the $\mathrm{Y}$ axis as the ratio of two elements, and set the equation as $\mathrm{y}=\mathrm{kx}$ $+\mathrm{b}$. We can bring in the value to get:

$$
\left\{\begin{array}{l}
228 / 102=9 \mathrm{k}+\mathrm{b} \\
125 / 119=2 \mathrm{k}+\mathrm{b}
\end{array}\right.
$$

The solution is $k=0.1693 ; b=0.7118$.

Thus, the equation is: $\mathrm{y}=0.1693 \mathrm{x}+0.7118$.

After finding the above equation, the ratio of the paired elements is brought into the equation. Further, the importance of the pair of elements can be solved. It is worth noting that since this equation is a linear equation, the ratio of elements should all be greater than 1 . The contrast of each pair of elements is:

Environmental factors: Lighting adjustment

$\mathrm{C}_{1} /$ Air purification $\mathrm{C}_{2}=6$

Man-machine factor: Height adjustment

$\mathrm{C}_{3} /$ Sitting posture correction $\mathrm{C}_{4}=5$

Working factors: Sedentary reminder

$\mathrm{C}_{6} /$ status recognition $\mathrm{C}_{5}=7$

Planning work $\mathrm{C}_{7} /$ status recognition $\mathrm{C}_{5}=6$

Sedentary reminder $\mathrm{C}_{6} /$ planning work $\mathrm{C}_{7}=2$

\subsection{Single group weight calculation}

Before performing total hierarchical sorting, we need to perform a single-level sorting on each set of data. The specific calculation process is the same as the criterion layer weight calculation process. The calculation results of each group of data are as follows:

Table 14. The Calculation of environmental factors

\begin{tabular}{llllllll}
\hline $\mathrm{B}_{1}$ & $\mathrm{C}_{1}$ & $\mathrm{C}_{2}$ & $\omega_{i}^{\prime \prime}$ & $\omega_{\mathrm{i}}$ & $\lambda_{\max }$ & C.I. & R.I. \\
\hline $\mathrm{C}_{1}$ & 1 & 6 & 1.7143 & 0.8572 & 2 & 0 & 0 \\
\hline $\mathrm{C}_{2}$ & $1 / 6$ & 1 & 0.2857 & 0.1429 & & & \\
\hline
\end{tabular}

Table 15. The Calculation of human-machine factors

\begin{tabular}{cccccccc}
\hline $\mathrm{B}_{2}$ & $\mathrm{C}_{3}$ & $\mathrm{C}_{4}$ & $\omega_{i}^{\prime \prime}$ & $\omega_{\mathrm{i}}$ & $\lambda_{\max }$ & C.I. & R.I. \\
\hline $\mathrm{C}_{3}$ & 1 & 5 & 1.6667 & 0.8333 & & \multirow{2}{*}{0} & \multirow{2}{*}{0} \\
\hline $\mathrm{C}_{4}$ & $1 / 5$ & 1 & 0.3333 & 0.1667 & & & \\
\hline
\end{tabular}

Table 16. The Calculation of working factors

\begin{tabular}{ccccccccc}
\hline $\mathrm{B}_{3}$ & $\mathrm{C}_{5}$ & $\mathrm{C}_{6}$ & $\mathrm{C}_{7}$ & $\omega_{i}^{\prime \prime}$ & $\omega_{\mathrm{i}}$ & $\lambda_{\max }$ & C.I. & R.I. \\
\hline $\mathrm{C}_{5}$ & 1 & $1 / 7$ & $1 / 6$ & 0.2110 & 0.0703 & 3.0242 & 0.0121 & 0.0233 \\
\cline { 1 - 5 } $\mathrm{C}_{6}$ & 7 & 1 & 2 & 1.7403 & 0.5801 & & & \\
\cline { 1 - 5 } $\mathrm{C}_{7}$ & 6 & $1 / 2$ & 1 & 0.8458 & 0.3496 & & & \\
\hline
\end{tabular}

\subsection{Calculation of total ranking weights}

According to the above calculation results, we can construct a hierarchy total ranking judgment matrix, and calculate the functional weights of each measure layer based on the formula (6). The judgment matrix is as follows:

$$
\omega_{i}=\sum_{j=1}^{m} a_{j} b_{i j}(i=1,2, \ldots, n)
$$

Table 17. Hierarchical total ranking judgment matrix

\begin{tabular}{llll}
\hline Hierarchy & $\mathrm{B}_{1}$ & $\mathrm{~B}_{2}$ & $\mathrm{~B}_{3}$ \\
$\begin{array}{l}\text { Criteria layer } \\
\text { weighted value }\end{array}$ & 0.1638 & 0.5390 & 0.2972 \\
\hline $\mathrm{C}_{1}$ & 0.8572 & 0 & 0 \\
$\mathrm{C}_{2}$ & 0.1429 & 0 & 0 \\
$\mathrm{C}_{3}$ & 0 & 0.8333 & 0 \\
$\mathrm{C}_{4}$ & 0 & 0.1667 & 0 \\
$\mathrm{C}_{5}$ & 0 & 0 & 0.0703 \\
$\mathrm{C}_{6}$ & 0 & 0 & 0.5801
\end{tabular}




\begin{tabular}{llll}
$\mathrm{C}_{7}$ & 0 & 0 & 0.3496 \\
\hline
\end{tabular}

According to Formula (6), the following is obtained:

$$
\omega_{C 1}=\sum_{j=1}^{3} \mathrm{~b}_{\mathrm{j}} \mathrm{c}_{1 \mathrm{j}}=
$$

$0.1638 \times 0.8572+0.5390 \times 0+0.2972 \times 0=0.1404$

$$
\omega_{C 2}=\sum_{j=1}^{3} b_{j} c_{2 j}=
$$

$0.1638 \times 0.1429+0.5390 \times 0+0.2972 \times 0=0.0234$

$$
\omega_{C 3}=\sum_{j=1}^{3} \mathrm{~b}_{\mathrm{j}} \mathrm{c}_{3 \mathrm{j}}=
$$

$0.1638 \times 0+0.5390 \times 0.8333+0.2972 \times 0=0.4491$

$$
\omega_{C 4}=\sum_{\mathrm{j}=1}^{3} \mathrm{~b}_{\mathrm{j}} \mathrm{c}_{4 \mathrm{j}}=
$$

$0.1638 \times 0+0.5390 \times 0.1667+0.2972 \times 0=0.0899$

$$
\omega_{C 5}=\sum_{j=1}^{3} b_{j} c_{5 j}=
$$

$0.1638 \times 0+0.5390 \times 0+0.2972 \times 0.0703=0.0209$

$$
\omega_{C 6}=\sum_{j=1}^{3} b_{j} c_{6 j}=
$$

$0.1638 \times 0+0.5390 \times 0+0.2972 \times 0.5801=0.1724$

$$
\omega_{C 7}=\sum_{\mathrm{j}=1}^{3} \mathrm{~b}_{\mathrm{j}} \mathrm{c}_{7 \mathrm{j}}=
$$

$0.1638 \times 0+0.5390 \times 0+0.2972 \times 0.3496=0.1039$

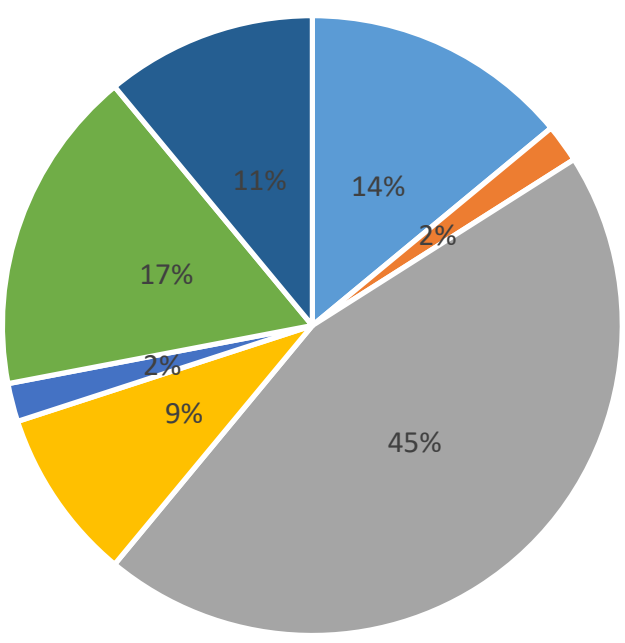

- Lighting adjustment

- Air pollution

- Height adjustment

घitting posture correction

- State seperation

- Sedantary reminder

- Work planning

Figure 5. The weight ratio of each element in the hierarchy total order.

The final result shows that the expectations of office staff for the function of healthy office furniture from high to low are height adjustment (45\%), sedentary reminder (17.2\%), and LED lights that can automatically adjust the light on the desktop (14\%), planning tasks to improve work efficiency (10.4\%), identifying and correcting bad sitting posture $(9 \%)$, surrounding air purification function $(2.3 \%)$, distinguishing between busy and leisure state (2.1\%).

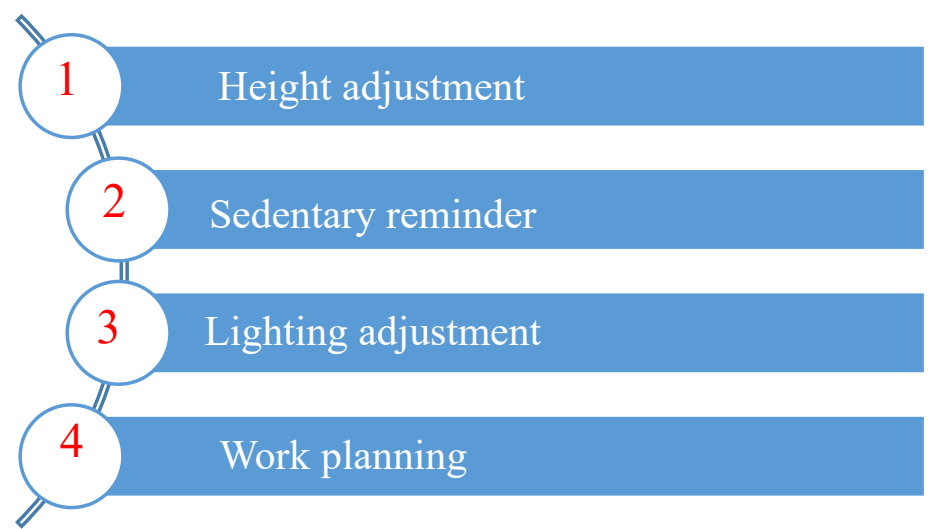

Figure 6. Functional ordering of healthy office furniture. 


\section{Conclusions}

The determination of the importance of the function can help the designer to distinguish between the primary and the secondary, and it can also help designers to distribute the energy reasonably. It is easier for users to increase satisfaction. We use analytic hierarchy process to prioritize the functions of the products, and finally determine the order of the functions of the healthy office furniture including the height adjustment function, the sedentary reminder function, the lighting adjustment function, and the planning task function.

Appendix: Importance evaluation scale for functions of healthy office furniture

\section{Importance evaluation scale for functions of healthy office furniture}

$\mathrm{Hi}$, thank you for engagement in this survey on the importance of functions of healthy office furniture. Please rate the importance of the functions below.

How important is the function lighting adjustment to you?

$\begin{array}{llllllll}1 & 2 & 4 & 5 & 6 & 7 & 8 & 9\end{array}$

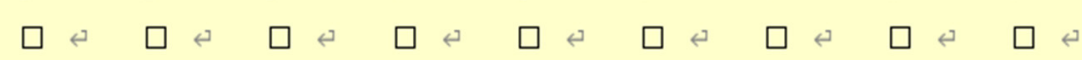

How important is the function air purification to you?

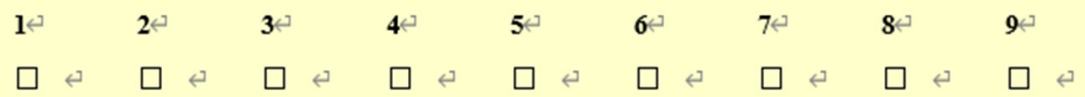

How important is the function height adjustment to you?

$\begin{array}{lllllllll}1 & 2 & 3 & 4 & 5 & 6 & 7 & 8 & 9\end{array}$

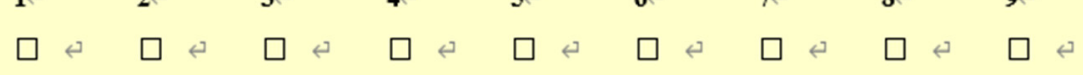

How important is the function sitting posture correction to you?

$\begin{array}{lllllllll}1 & 2 & 3 & 4 & 5 & 6 & 7 & 8 & 9 \\ \square & \square & \square & \square & \square & \square & \square & \square & \square\end{array}$

How important is the function state separation to you?

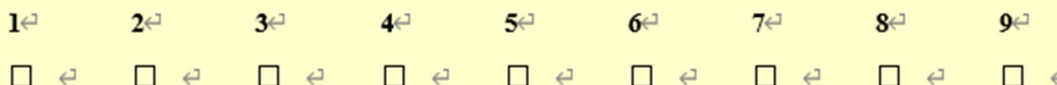

How important is the function sedentary reminder to you?

\begin{tabular}{|c|c|c|c|c|c|c|c|c|c|c|c|}
\hline 1 & 2 & 3 & 4 & 5 & 6 & & 7 & & 8 & & 9 \\
\hline$\square \hookleftarrow$ & $\square$ & $\square$ & $\square$ & $\square$ & $\square$ & 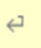 & $\square$ & 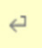 & $\square$ & 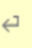 & $\square$ \\
\hline \multicolumn{12}{|c|}{ How important is the function work planning to you? } \\
\hline 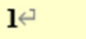 & 2 & 3 & 4 & 5 & 6 & & 7 & & 8 & & 9 \\
\hline$\leftrightarrow$ & $\square$ & $\square$ & $\square$ & $\square$ & $\square$ & 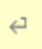 & $\square$ & $\leftrightarrow$ & $\square$ & $\leftrightarrow$ & $\square$ \\
\hline
\end{tabular}

\section{References}

1. Zhao bin, He Simeng.(2016)"The group of sedentary" The research of monitoring and reminding device of sitting posture. J. Design, (21):108-109.

2. He Xiaoyu. (1993)HID - Health industrial design--Alan Tye'design concept, who is the famous British royal industrial designer. J. Interior design and decoration, (04):4-5.
3. Qin Ji, Zhang Yipeng. (1999) Application of modern statistical information analysis technology in safety engineering_Principle of analytic hierarchy process. J. Industrial safety and dustproof,05:44-48.

4. Wang Chunpeng.(1010) A comparative study of green design and evaluation methods.J. Packaging engineering,31(16):78-80.

5. Saaty T. L. (2005) Analytic Hierarchy Process.J. Encyclopedia of Biostatistics, 1.

6. Xu Zeshui. (2000) A new method of judging matrix consistency correction. J. System engineering theory and practice, (04):86-89. 